\title{
Design of Remote Laboratory dedicated to E2LP board for e-learning courses.
}

\author{
Jan Piwiński \\ Przemysłowy Instytut Automatyki \\ i Pomiarów PIAP, Aleje \\ Jerozolimskie 202, 02-486 \\ Warszawa, Poland \\ Email: jpiwinski@piap.pl
}

\author{
Rafał Kłoda \\ Przemysłowy Instytut Automatyki \\ i Pomiarów PIAP, Aleje \\ Jerozolimskie 202, 02-486 \\ Warszawa, Poland \\ Email: rkloda@piap.pl
}

\author{
Roman Szewczyk \\ Przemysłowy Instytut Automatyki \\ i Pomiarów PIAP, Aleje \\ Jerozolimskie 202, 02-486 \\ Warszawa, Poland \\ Email: rszewczyk@piap.pl.
}

\begin{abstract}
Recently, with advent and exploitation of computer and communication technologies, remote laboratories have been widely popular among many universities. They are built in order to enhance learning and minimize the gap between theory and practice. Remote laboratories provide on-line pervasive workbenches, which allow an interactive learning environment that maintains student attention. This paper reports on development of remote laboratory, which is currently performing under E2LP FP7 project. The paper addresses many solutions in the development stages along with powerful technologies involved. E-learning portal will create and provide new teaching methods in embedded systems design through the real and simulated experiments.
\end{abstract}

\section{INTRODUCTION}

Laboratories, which are found in all engineering and science programs, are an essential part of the education experience. Not only do laboratories demonstrate course concepts and ideas, but they also bring the course theory into alive. In a traditional laboratory, the user interacts directly with the equipment by performing physical actions (e.g. manipulating with the hands, pressing buttons, turning knobs) and receiving sensory feedback (visual and audio). However, equipping a laboratory is a major expense and its maintenance can be difficult. [1]

Since the experiments are performed in a laboratory that contains expensive equipment, the students must be supervised which limits the time they have. This also requires a class with many groups performing the experiment at the same time, and thus many instruments are required to support each group. Laboratory experiments are also a serious problem for distance learning students who may not have an access to the laboratory at all. [2]

As an alternative, virtual online laboratories can expose students to hands-on learning without incurring the high costs of instructional facilities. [3]

Remote laboratories are those laboratories that can be controlled and administrated online. They differ from the virtual simulated laboratories as they are interacting with physical instruments. [4]

\section{REMOTE LABORATORY}

In E2LP (Embedded Computer Engineering Learning Platform) project [5] a Remote Laboratory (RL) is an experiment, demonstration and a process running locally to design and control an experiment board based on a FPGA device, but with the ability to be monitored and controlled over the Internet (future E-learning portal).

In the base case, the RL can be an experiment board connected to a computer through a standard interface and with the host computer connected to the Internet, which provide remote access. The client can be any computer connected to the Internet with an ability to see the same interface as the local host and also have the same programs, interfaces, modules etc.

The concept of E2LP RL should allow the user to do several actions over an Internet connection, which are the list of E2LP Remote Laboratory functionalities:

1. Dedicated software and hardware solutions will provide an access to laboratory equipment and enable students to set them up and operate them at the required level to carry out exercises.

2. Users could access the essential data sheets, tutorials and software tools, which are available on the E-learning portal as an introduction to the course, which is a RL's content management system (CMS). Each laboratory exercise is presented to the user through tabs and such division will be implemented into Moodle based platform for e-learning course (Basic information, Theoretical explanations Instructions, Feedback questionnaire for lab evaluation).

3. After booking in a given time space Users could remotely program given set of exercises over the Internet and simultaneously, in real time could monitor the evolution of the experiment on implemented dedicated Graphical User interface (GUI) of the Front Panel of the board. Fig. 1

4. Automatic verification of course assignments, supported by Moodle plug-in, will allow an advanced management of assignments and submissions together with feedback information mechanisms for both teachers and stu- 
dents, which will verify whether the students designs work or not according to the specifications.

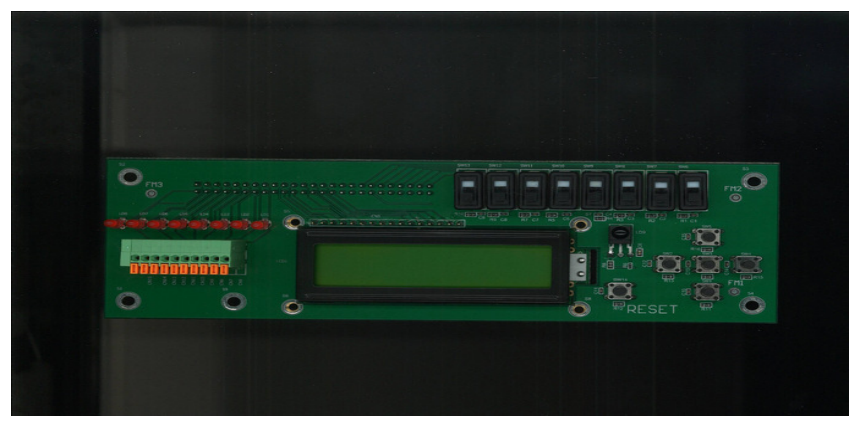

Fig. 1 E2LP board Front Panel

The main advantage of E2LP Remote Laboratory is when students interact with the dedicated boards UI, implemented as a web service and work with software applications, they are actually operating the same tools and instruments like they would be in classic lesson in laboratory.

$\mathrm{RL}$ is a gate which provide an access to continuously refreshed interfaces and signals from the real board and enable user remotely control and program the board directly from their computer at home, having instant visual feedback.

To achieve this, it is necessary to forward data directly to the server over common interfaces or over local network by using dedicated hardware solutions and specified proper router configuration.

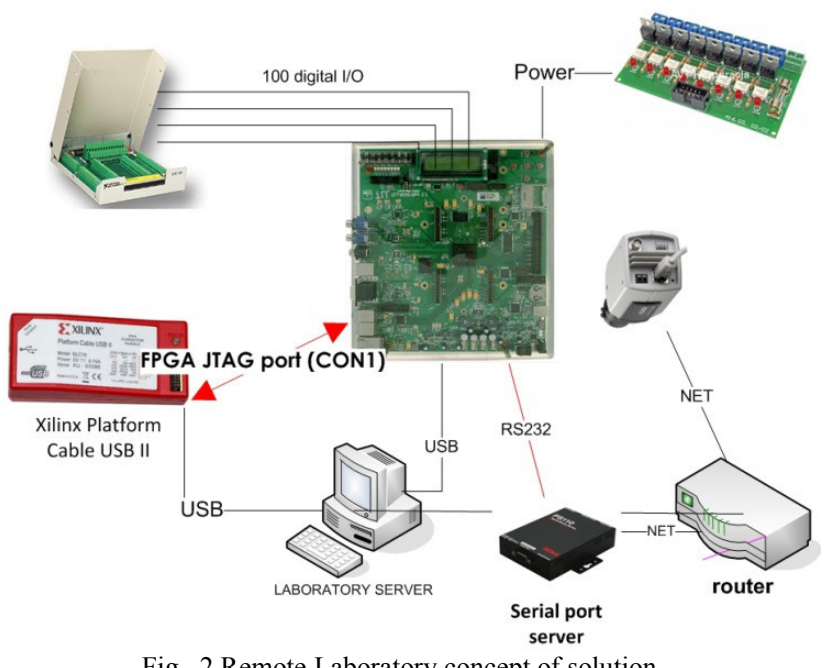

Fig. 2 Remote Laboratory concept of solution

The Fig. 2 above presents remotely controlled environment concept of solution. The whole environment is managed by powerful E2LP Server, which is equipped with all common interfaces, which are essential for internal hardware and software compatibility. E2LP Server is connected via Ethernet interface to the local network, which is responsible for seamless data communication between environment's components. The crucial component of the remotely controlled environment is an experiment base board, which is controlled by programming device (Xilinx Platform HWUSB-II-G). This programming device provides integrated firmware to deliver high-performance, reliable and userfriendly configuration of the base board and enables user to program other Xilinx CPLD devices. This programming device is fully integrated and optimized for use with specialized Xilinx iMPACT software, which enable users to perform remote operations such as programming and configuring FPGA via JTAG interface.

The NI PCI-6509 digital card with 96 bidirectional I/O lines enable user by dedicated GUI interface (Error: Reference source not found) to control each pin in the boards front panel interface and consequently enable him to control each led, switch and button. Furthermore specific module communicates with LCD pins on boards front panel interface and translate them into RS232 ASCII chars.

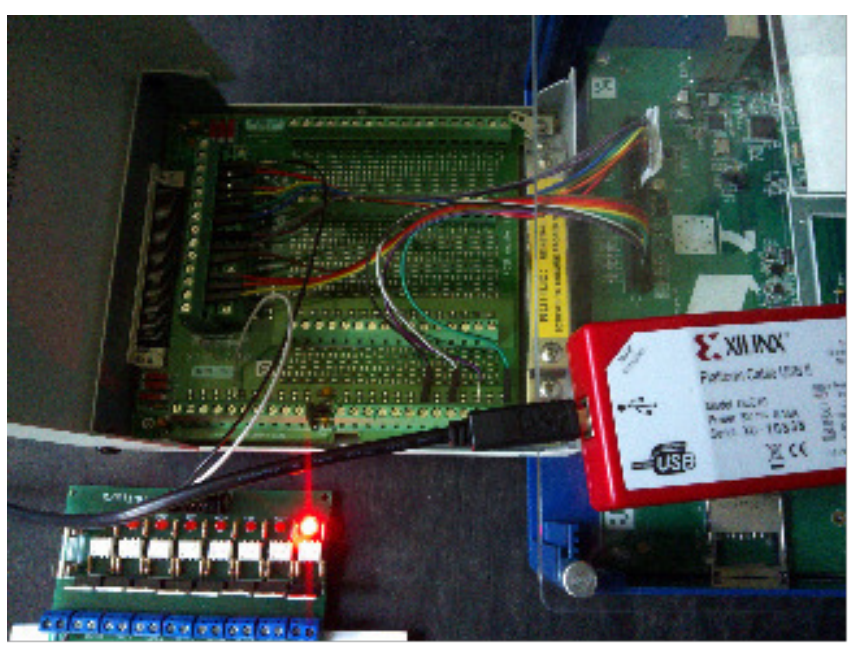

Fig. 3 NI PCI-6509 digital card integration with E2LP board front Panel

In remote operations user firstly power the board from the website (this is done by power controller module and digital card) and run iMPACT on one computer but the operations are performed on a device attached to another computer through a Xilinx Cable Server. Xilinx ISE includes such program as well as provide a set of programming tools, which allow user to perform operations remotely. To use this functionality user only needs to specify a remote server address in proper configuration in iMPACT software. This is the most important feature of programming device, from the RL point of view.

It should be pointed that all exercise could be done remotely, but feedback from some interfaces is not available. Error: Reference source not found below represents implemented necessary interfaces according to requirements.

Connection with the Remote Laboratory is provided via e-learning portal and is based on Apache server, PHP and SQL server. It provides an access to knowledge (exercises, data sheets) through a web user interface and has an ability 
TABLE I

IMPLEMENTED INTERFACES IN RL

\begin{tabular}{|c|c|c|c|}
\hline \multicolumn{2}{|c|}{ Component } & \multirow{2}{*}{$\begin{array}{l}\text { Implementation } \\
\text { in RL }\end{array}$} & \multirow{2}{*}{$\begin{array}{c}\text { Access to } \\
\text { the } \\
\text { interface }\end{array}$} \\
\hline Type & $\begin{array}{l}\text { Direction } \\
\text { (In/Out) }\end{array}$ & & \\
\hline $\begin{array}{c}\text { LCD 16x2 } \\
\text { Character } \\
\text { Display }\end{array}$ & $f / 0$ & $\begin{array}{c}\text { (Not-tested) } \\
\text { Full }^{1}\end{array}$ & GUI \\
\hline $\begin{array}{c}\text { Dip } \\
\text { Switches }\end{array}$ & $\boldsymbol{\sigma} / \mathbf{f}$ & Full & GUI \\
\hline $\begin{array}{c}\text { Push } \\
\text { Buttons }\end{array}$ & $\mathbf{b} / \mathbf{f}$ & Full & GUI \\
\hline LED & $f / c$ & Full & GUI \\
\hline RS-232 & $0 / 0$ & Full & $\begin{array}{c}\text { Standard } \\
\text { tool }^{2}\end{array}$ \\
\hline $\begin{array}{c}\text { Power } \\
\text { Supply } \\
\text { ON/OFF }\end{array}$ & $\boldsymbol{v} / \mathbf{f}$ & Full & GUI \\
\hline & $\begin{array}{r}{ }^{1}-\text { now ur } \\
- \text { e.g. Hype } \\
\text { GUI - }\end{array}$ & $\begin{array}{l}\text { ler development } \\
\text { erminal, Putty, etc. } \\
\text { veb interface }\end{array}$ & \\
\hline
\end{tabular}

to exchange information between laboratory hardware and software applications. The second role of e-learning portal is management of users, which menas enable them access to the laboratory hardware and software (booking functionality and authorization). In E2LP project the e-learning platform is based on Moodle Platform, which is one of the most popular open source learning management systems.

\section{SCENARIO OF USAGE RL}

For remote operations user is provided user manual guideline, dedicated software and an access to laboratory equipment, which enable students to set them up and carry out exercises. Our aim was to provide instant feedback to the board in a way that user would work with the real board as if it was connected locally. This functionality was a purpose to developed GUI web interface of front panel that exactly looks like the real board, which has connections to real signals from the real board. States of the physical signals are continuously refreshed at defined times $(250 \mathrm{~ms})$ and tests confirmed that it is sufficient to inform the user (by observing GUI) that his program - made during the lab exercise works correctly. Below we described current scenario of RL usage during the exercise of design the logic circuits:

- User write code of his program according to exercise on local Xilinx ISE environment

- Generate bit file

- Remotely configure FPGA (setup the board, power up, connect the programming modules, )
- Test solution using GUI and standard tool

In the design of digital systems logic circuits are used as fundamental components. TABLE II presents the NAND (Negated AND or NOT AND) logic table its truth table inherited from Boolean algebra. After setting the input voltages to the desired values (low or high), these circuits are capable of calculating values of Boolean functions they represent and present the results of Boolean functions on their outputs. and this exercise will not go into detail on how these circuits are implemented.

TABLE II

NAND LOGIC TABLE

\begin{tabular}{|l|l||c|c|c||}
\hline & $\mathrm{X}_{1}$ & $\mathrm{X}_{2}$ & $\mathbf{Y}$ \\
\hline & 0 & 0 & $\mathbf{1}$ \\
\hline & 0 & 1 & $\mathbf{1}$ \\
\hline & 0 & 1 & 0 & $\mathbf{1}$ \\
\hline & & 1 & 1 & $\mathbf{0}$ \\
\hline
\end{tabular}

System entity represents the system as seen from outside. Imagine observing the system on Fig. 4 from outside, without the possibility to see what is inside the system. The only things you will see are its input and output ports. Input ports are like input variables to a function, while output ports are like results of the functions. Each output port in a combinational digital system represents the result of one Boolean function of input ports. If the system has $\mathrm{N}$ output ports and $\mathrm{M}$ input ports, it computes $\mathrm{N}$ Boolean functions of $\mathrm{M}$ variables, i.e. functions of the same input ports.

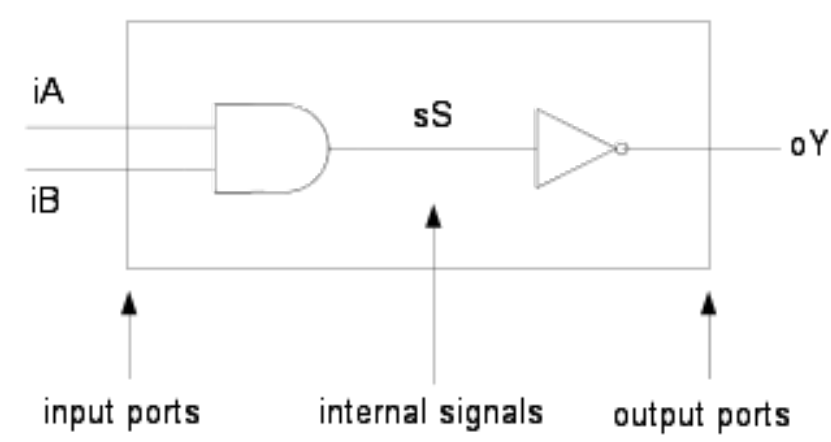

Fig. 4 An example of the digital system

In order for the tool to know to which components on the board we want to connect inputs and outputs of our system, we need to specify which pin from FPGA we want to associate with which port of our system. Let us connect inputs $\mathrm{iA}$ and $\mathrm{iB}$ to two switches and output oY to a LED. You can always refer to the complete list of FPGA pins on E2LP platform and to which components they are connected. Pin assignment is done in a special tool for that, the Xilinx PlanAhead. It can be run from Xilinx ISE. 
Future development of RL based on integration of external equipment and services and development of Moodle platform will be done in accordance with the exercises necessities and end-users needs. .

\section{REFERENCES}

[1] Distance-Learning Remote Laboratories using LabVIEW; Publish Date: Sep 06, 2006 http://www.ni.com/white-paper/3301/en/

[2] A. Nafalski, J. Machotka, Z. Nedic "Collaborative Remote Laboratory NetLab for Experiments in Electrical Engineering", in
Using Remote Labs in Education. Two Little Ducks in Remote Experimentation, 2011, University of Deusto, pp. 177-199

[3] S. Dutta, S. Prakash, D. Estrada, E. Pop "A Web Service and Interface for Remote Electronic Device Characterization" in IEEE Trans. Education Vol. 54 No. ,4 pp. 646-651

[4] M. Tawfik, E. Sancristobal, S. Martin, G. Diaz, M. Castro: "State-ofthe-Art Remote Laboratories for Industrial Electronics Applications" in Technologies Applied to Electronics Teaching (TAEE), 2012, pp. $359-364$

[5] http://www.e2lp.org/ 